\title{
Detection and Evaluation of Intracranial Aneurysms with 3D-CT Angiography and Compatibility of Simulation View with Surgical Observation
}

\author{
$\ddot{U}$ Ç Boyutlu BT Anjiyografi ile Intrakraniyal Anevrizmalarn \\ Değerlendirilmesi ve Simülasyon Görüntüleriyle Cerrahi \\ Görünümün Uygunluğu
}

Kenan KOC ${ }^{1}$, Burak CABUK ${ }^{1}$, İhsan ANIK ${ }^{1}$, Hasan Tahsin SARISOY², Sevtap GUMUSTAS², Ercument CIFTCI², Savas CEYLAN ${ }^{1}$

${ }^{1}$ Kocaeli University, School of Medicine, Department of Neurosurgery, Kocaeli, Turkey

${ }^{2}$ Kocaeli University, School of Medicine, Department of Radiology, Kocaeli, Turkey

Corresponding Author: Kenan KOC / E-mail: kenankoc01@yahoo.com

\begin{abstract}
AIM: The aim of this study was to report our experience with a 64-channel computerized tomography (CT) scanner as the primary choice on the detection of intracranial aneurysms. Comparison of intracranial aneurysms with the simulated images obtained via three-dimensional computed tomography angiography (3D-CTA) in pterional approach was also aimed.

MATERIAL and METHODS: Among 288 consecutive patients who had intracranial aneurysms detected on 64-slice CTA, a total of 337 aneurysms were detected. CTA simulation images and intraoperative images were compared with regards to size, shape, and orientation.

RESULTS: In one of the 22 CTA-negative cases, one aneurysm was detected in DSA and an additional aneurysm was detected in a patient operated with CTA. Aneurysm size, shape and direction were error free except a few cases. However, CTA was found to be insufficient to show particularly perforating arteries that were smaller than $2 \mathrm{~mm}$ in size.

CONCLUSION: As a fast and noninvasive technique, CTA can be used as an initial examination in subarachnoid hemorrhage. Keeping the fact that there can be insufficiency in showing particularly small aneurysms in mind, DSA should be performed on CTA-negative cases and required cases.
\end{abstract}

KEYWORDS: Aneurysm surgery, Cerebral aneurysm, CTA, SAH

Öz

AMAÇ: Çalışmada 64 kesit bilgisayarlı tomografi (BT) ile intrakraniyal anevrizmalar tetkik edildi. Üç boyutlu simülasyon görüntüleriyle pterional yaklaşımdaki anevrizmalar karşılaştırıldı.

YÖNTEM ve GEREÇLER: Altmış dört kesit BT anjiyografi yapılan 288 hastada, 337 anevrizma saptandı. BT anjiyografideki simülasyon görüntüleriyle intraoperatif anevrizma büyüklük, şekil ve yönelimi karşılaştırıldı.

BULGULAR: BT anjiyografi negatif olan 22 hastadan birinde dijital anjiyografide, bir olguda ise cerrahi sırasında ek anevrizma saptandı. Anevrizma boyut, şekil ve yönelim olarak çok az olgu dışında hatasızdı. BT anjiyografi $2 \mathrm{~mm}$ den küçük perforanları göstermede yetersiz kaldı. SONUÇ: Hızlı ve noninvaziv bir tetkik olarak BT anjiyografi ilk tetkik olarak subaraknoid kanamda kullanılabilir. Küçük damarları göstermedeki yetersizliği akılda tutularak BT anjiyografi negatif olgularda ve gerekli olgularda dijital anjiyografi yapılmalıdır.

ANAHTAR SÖZCÜKLER: Anevrizma cerrahisi, Beyin anevrizması, BTA, Subaraknoid kanama

\section{INTRODUCTION}

Digital subtraction angiography (DSA) is the preferred method for detecting patients with subarachnoid hemorrhage $(\mathrm{SAH})$. Although it is the gold standard technique, it has the disadvantage of being invasive, and has a low but significant complication risk rate of $1 \%$ and a neurological deficit rate of $0.07-1 \%(5,9)$. Thus new, noninvasive, rapid, precise, cheap and applicable modalities are required for the diagnosis of intracranial aneurysms.
Computed tomography angiography (CTA) using multidetector CT scanning has been developed, which has increased the sensitivity to detect aneurysms. Three-dimensional computed tomography angiography (3D-CTA) is a fast, noninvasive and reliable method that seems to possibly replace DSA in the initial diagnosis of ruptured or unruptured aneurysms. 3D-CTA has the advantages of being non-invasive, readily available, inexpensive, performing quick reconstruction of 3-D images that allows the surgeon to rotate the images to 
become surgical view images. CTA facilitates more accurate understanding of the anatomical relationships between the aneurysm neck and the adjacent vasculature. Hence, 3D-CTA is to take the place of DSA for diagnosis and treatment management of intracranial aneurysms $(2,6,8,12)$.

Knowing the detailed anatomic configurations of cerebral aneurysms is among the main factors affecting surgical clipping. The introduction of 64-channel CT scanners has greatly advanced the role of CTA in neurovascular imaging. The objective of this study was to report our experience with a 64-channel CT scanner as the primary choice in the detection of intracranial aneurysms. In addition, operative evaluation of specific intracranial aneurysms was compared with the simulated images obtained via 3D-CTA in patients with cerebral aneurysms.

\section{PATIENTS-METHODS}

Patients: Between April 2007 and April 2013, a total of 337 aneurysms were detected in 288 patients with CTA Informed consent was obtained from patients or the relatives if patients had difficulty in responding on their own and approval of the local human investigations committee was also received. The patients consisted of 152 women and 136 men with an age range of 14-71 years and a mean age of 53.8 years. Clinical conditions of the patients were classified according to the WFNS grading system. Twenty-two patients were classified as grade 0,132 as grade 1, 89 as grade 2, 27 as grade 3, 11 as grade 4 , and 7 as grade 5 (Table I).

Imaging: As the primary examination, 3D-CTA was performed for patients with SAH within 1-6 hours after admission. DSA was performed in case CTA findings were negative or in the presence of aneurysm with conditions such as giant aneurysm, complex aneurysm and in the achievement of

Table I: Clinical Data of 288 Consecutive Patients

\begin{tabular}{|l|c|}
\hline $\begin{array}{l}\text { Clinical Characteristic } \\
\text { Age (Years) }\end{array}$ & Value \\
range & $14-71$ \\
\hline mean \pm SD & 53.8 \\
\hline Sex & \\
\hline male & 136 \\
female & 152 \\
\hline WFNS grade & \\
\hline O & 22 \\
\hline I & 132 \\
II & 89 \\
III & 27 \\
IV & 11 \\
V & 7 \\
\hline *SD = standard deviation; WFNS = World Federation of Neurosurgical \\
Societies
\end{tabular}

further hemodynamic information. When CTA and DSA findings of both modalities were negative, a second DSA was planned three weeks later. The CTA and DSA images were assessed on monitor or on a hard copy film by a team that consisted of three radiologists and three neurosurgeons. In discordant or complex cases, a definitive unique result was reached by consensus.

\section{CTA Imaging}

Scanning and reconstruction protocol: All patients were scanned with 64-row multislice computed tomography system (Toshiba Aquilion 64; Toshiba Medical Systems; Japan). The imaging parameters were $120 \mathrm{kVp}, 250 \mathrm{~mA}, 125 \mathrm{mAs}$ with a collimation of $64 \times 0.5 \mathrm{~mm}$, and a rotation time of 0.5 seconds. Image reconstruction parameters were as follows: section thickness of $0.5 \mathrm{~mm}$, overlapping steps of $0.3 \mathrm{~mm}$, and field of view (FOV) of $120 \mathrm{~mm}^{2}$. After brain scanning without contrast administration, all patients were scanned with intravenous contrast application for enhancing intracranial vessels. An iodine contrast medium of $100 \mathrm{~mL}$ with a concentration of $300 \mathrm{mg}$ lodine per $\mathrm{mL}$ (Omnipaque ${ }^{\circledR} 300 \mathrm{mg}$ I/ml, Amersham health, Ireland) was used. Infusions were performed with an automatic injector system (Mallinckrodt automatic injector). The infusion rate was adjusted as $4 \mathrm{~mL} / \mathrm{sec}$. A bolus tracking method was used for synchronization of contrast medium and scanning time.

Analysis of CT angiograms: Following the completion of scanning, all the data sets were sent to the workstation (Vitrea 2; Vital) for further image analysis. Prior to multiformat and 3D analysis, all the source data were examined thoroughly. Axial, coronal and sagittal plane multiformat images were created. Maximum intensity projection (MIP) images with multiple thickness adjustment were achieved in all orthogonal planes. The volume rendering technique (VRT) was performed using the subset of volume data including the circle of Willis. Multiple snapshot photo files and video files from 3D volume rendering workup were obtained. All CTA images were reviewed by one experienced radiologist (HT.S). Three dimensional images that were suitable for the surgical position were created to determine the position, shape and orientation of the aneurysms by using the workstation. When necessary, bone processes within the surgical observation angle were removed.

DSA imaging: Cerebral DSA was performed after multidetector CT angiography by an interventional radiologist as soon as this was clinically feasible. DSA was performed with a digital angiography unit (Toshiba Infinix VC-i, Toshiba medical systems corporation) with a $1024 \times 1024$ pixel matrix. The angiographic procedure was routinely accomplished with a standard diagnostic catheter. Bilateral selective internal carotid artery and vertebral artery injections were performed and imaged in Town, oblique and lateral projections with a contrast injection rate of $5 \mathrm{ml} / \mathrm{sec}$ and $10 \mathrm{ml}$ in each vessel (Omnipaque ${ }^{\circledR} 350 \mathrm{mg} \mathrm{l} / \mathrm{ml}$, Amersham health, Ireland). Additional angiographic images were acquired on the basis of the findings in the routine projections of DSA and the multidetector CT angiography results. Increased magnification was used for 
the aneurysm portion when necessary. DSA images were reviewed at the workstation. All the DSA images were reviewed in consensus by two experienced radiologists (E.C., S.G.).

\section{Surgery}

Two hundred and ninety one aneurysms were treated by pterional craniotomy. In the cranial surgery position, simulation clips served as a guide for the $x, y$ and $z$ axis angles in all patients. $X, Y$ and $Z$ values on the simulation clips were not mathematically considered. After examining the MIP and biplanar images, the aneurysm view was rotated for $360^{\circ}$ with VRT to see the neck, dome and shape, and the parent arteries were also noted. By taking the sphenoid ridge, planum sphenoidale axis and anterior clinoid process as the bases, video clips of aneurysms within the surgical view were created. According to the bone landmark, the head was positioned by using a Mayfield Headrest. Later on, different angles were outlined and finally simulation clips added on optimal surgical approach angle were put out to clarify the pathology in 3D view for the neurosurgeon. Pictures and moving images were reevaluated by the neurosurgical team in the operating theatre. Microscopic images were compared with radiological images after demonstrating the aneurysm surgically.

\section{RESULTS}

A total of 337 aneurysms were identified in 288 patients with 3D-CTA. Two hundred and forty seven patients had one, thirty five patients had two, four patients had three and two patients had four aneurysms. The rate of multiple aneurysms was $14.23 \%$. On 3D-CTA images, aneurysm size ranged from 2 to $32 \mathrm{~mm}$ (mean size $8.4 \mathrm{~mm}$ ) and 32 aneurysms were shorter than $3 \mathrm{~mm}, 71$ were between 3 and $5 \mathrm{~mm}, 132$ were 5-10 mm, 88 were $10-20 \mathrm{~mm}$ and 14 were over $20 \mathrm{~mm}$. The most frequent aneurysm location was the middle cerebral artery (MCA) followed by the anterior communicating artery (AComA) as shown in Table II.

A total of fifty patients underwent both 3D-CTA and DSA. For 22 patients with negative 3D-CTA, DSA was performed after 1-2 days. One aneurysm was detected at first DSA, which was located in the middle cerebral artery MCA. After reevaluation of the 3D-CTA, aneurysms could be demonstrated on 3D-CTA. The MCA aneurysm ( $2 \mathrm{~mm}$ ) was at close proximity of the sphenoid ridge. For 21 patients with negative DSA and 3D-CTA, the second angiography was conducted after 20 days and no other aneurysms were identified. For 28 patients, in whom aneurysms were detected (5 giant aneurysms, 9 complex aneurysms, 8 basilar apex aneurysms, 5 Posterior inferior cerebellar artery (PICA) aneurysms, 4 Posterior cerebral artery (PCA) aneurysms), a DSA was performed.

Patients ( $n=247$ ) who were diagnosed only with CTA underwent surgery for clipping 291 aneurysms with a pterional approach. The operation time interval after admission with SAH was the first 1 day in 124 patients, 1-3 days in 87 patients and more than 3 days in 36 patients. There was one additional aneurysm found in the surgery. The PCoA aneurysm, which was
Table II: Location and number of cerebral aneurysms (CTA)

\begin{tabular}{|l|c|}
\hline Location & $\begin{array}{c}\text { Number of } \\
\text { Aneurysm(\%) }\end{array}$ \\
\hline Middle cerebral artery & $121(35.9)$ \\
\hline Anterior communicating artery & $103(30.7)$ \\
\hline Internal carotid artery & $44(13)$ \\
\hline Posterior communicating artery & $37(10.9)$ \\
\hline Anterior cerebral artery & $15(4.4)$ \\
\hline Basilar artery & $8(2.4)$ \\
\hline Posterior inferior cerebellar artery & $5(1.5)$ \\
\hline Posterior cerebral artery & $4(1.2)$ \\
\hline
\end{tabular}

$\mathbf{n}=288$, total 337 aneurysms

small in size ( $3 \mathrm{~mm}$ ), was located close to the clinoid process. Fifteen distal ACA aneurysms in 13 patients were treated via the interhemispheric approach. The remaining 17 patients ( 8 basilar aneurysms, 5 PICA aneurysms, 4 PCA aneurysms) were treated via the endovascular procedure.

\section{Intraoperative and 3D-CTA images in specific aneurysms}

MCA aneurysms: In 118 MCA aneurysms, the direction, shape, and size of the aneurysm obtained with 3D-CTA were found to correlate with intraoperative findings (Figure 1A, $B)$; however, imaging findings were not adequate for small lenticulostriate (LS) group arteries. It was not possible to show these arteries at the proximity of the aneurysm neck in CTA. The position and distance of aneurysm to sphenoid wing and orientation (frontal, temporal and posterior) were determined. The distance was especially increased in elderly patients after cerebrospinal fluid drainage. In addition if a brain retractor was used, the aneurysms were away from the sphenoid wing and deep into the Sylvian fissure, their orientation was observed to have changed

ACoA aneurysms: In 96 AComA aneurysms, the direction, shape, and size could be determined without error with 3D-CTA. However, in most cases special care is required for Heubner and other small perforating branches. These small vessels could not be seen in many cases on simulation clips (Figure $2 A, B$ ). During DSA, determination of dominant ACA in $A C o m A$ aneurysm is important in surgery. With CTA, dominant ACA was predicted by comparing both ACA calibrations. In addition, valuable information was obtained for successful clipping by prediction of the orientation of the aneurysm for planum sphenoidale

ICA aneurysms: Seventy-seven ICA aneurysm, CTA and intraoperative findings were similar in aneurysm direction, shape, and size (Figure 3A-D). Small neighboring vessels (small PCoA, superior hypophyseal artery, anterior choroidal arteries) could not be demonstrated clearly. In case of paraclinoid aneurysms, the anterior clinoid process and optic strut have been used as osseous landmarks to evaluate the neck of the aneurysm. CTA demonstrates both the neck of the 
aneurysm and these landmarks. The clinoid process and optic strut relationship is important in surgical decision making and strategy (Figure 4A-D). We observed no positional changes of these aneurysms after cerebrospinal fluid drainage, as the distal dural ring is tightly adherent to the ICA.

\section{DISCUSSION}

Catheter based cerebral angiography has been the main imaging modality for the diagnosis of intracranial aneurysms for many years. This examination is an expensive technology and highly specialized medical and paramedical personnel are required. The risk of complications is also not completely avoided (5). DSA fails to reveal an aneurysm at an approximate false-negative rate of $5-10 \%$, and this rate is generally due to physical limitations of the angiographic equipment that may make it difficult to obtain the optimum projection needed to detect some aneurysms $(7,25)$. Also, once an aneurysm is detected, accurate visualization and measurement of its neck and relationship to the parent artery may be difficult in some of cases, impairing selection of the optimum treatment method (22).
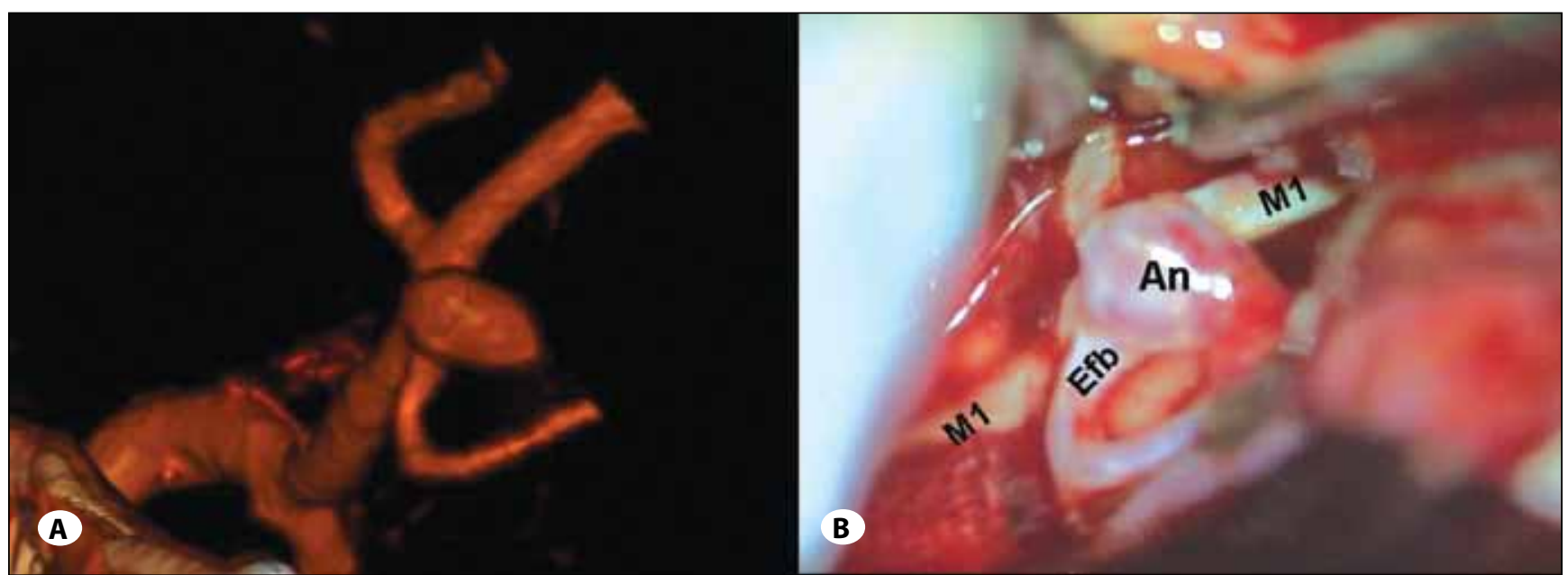

Figure 1: A) ) $5 \mathrm{~mm}$ diameter of right MCA aneurysm and the projection of the aneurysm is the temporal lobe at the early frontal branch location. B) Direction and shape of aneurysm after Sylvian dissection following proximal control at pterional approach, fully compatible with CTA. M1; 1st segment of Middle cerebral artery, Efb; Early branch of Middle cerebral artery, An; Aneurysm.

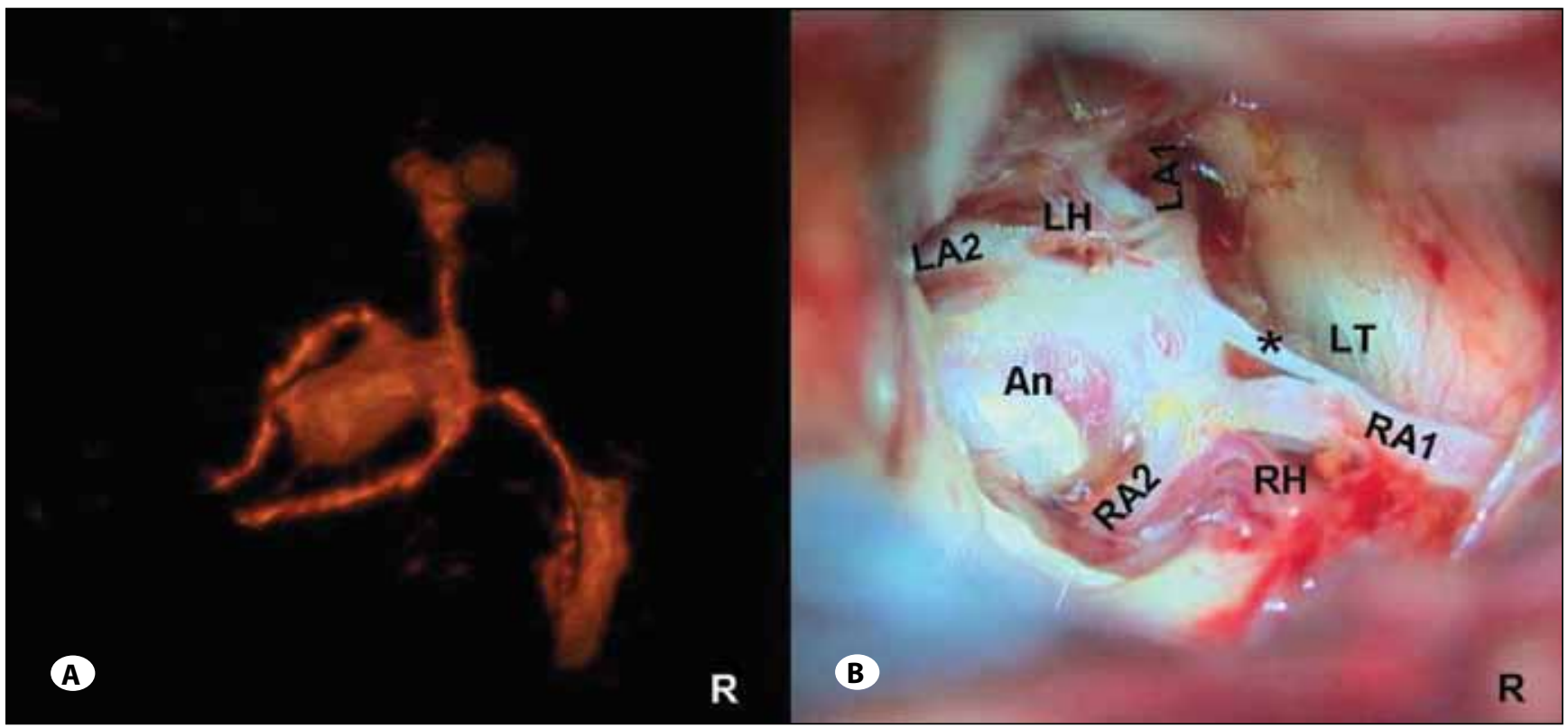

Figure 2: A) Three-dimensional CT angiography clearly demonstrates ACoA aneurysm of $14 \mathrm{~mm}$ diameter with superior projection. B) Intraoperative photograph shows superiorly located aneurysm, but also neighboring tiny part of fenestrated $A C o A$ and $0.5 \mathrm{~mm}$ Heubner that were not seen on CTA. RA1; right A1 segment of ACA, RA2; right A2 segment of ACA, LA1; left A1 segment of ACA, LA2; left A2, segment of ACA, LH; left artery of Heubner, RH; right artery of Heubner, LT; lamina terminalis, An; Aneurysm, *; fenestrated Anterior communicating artery. 


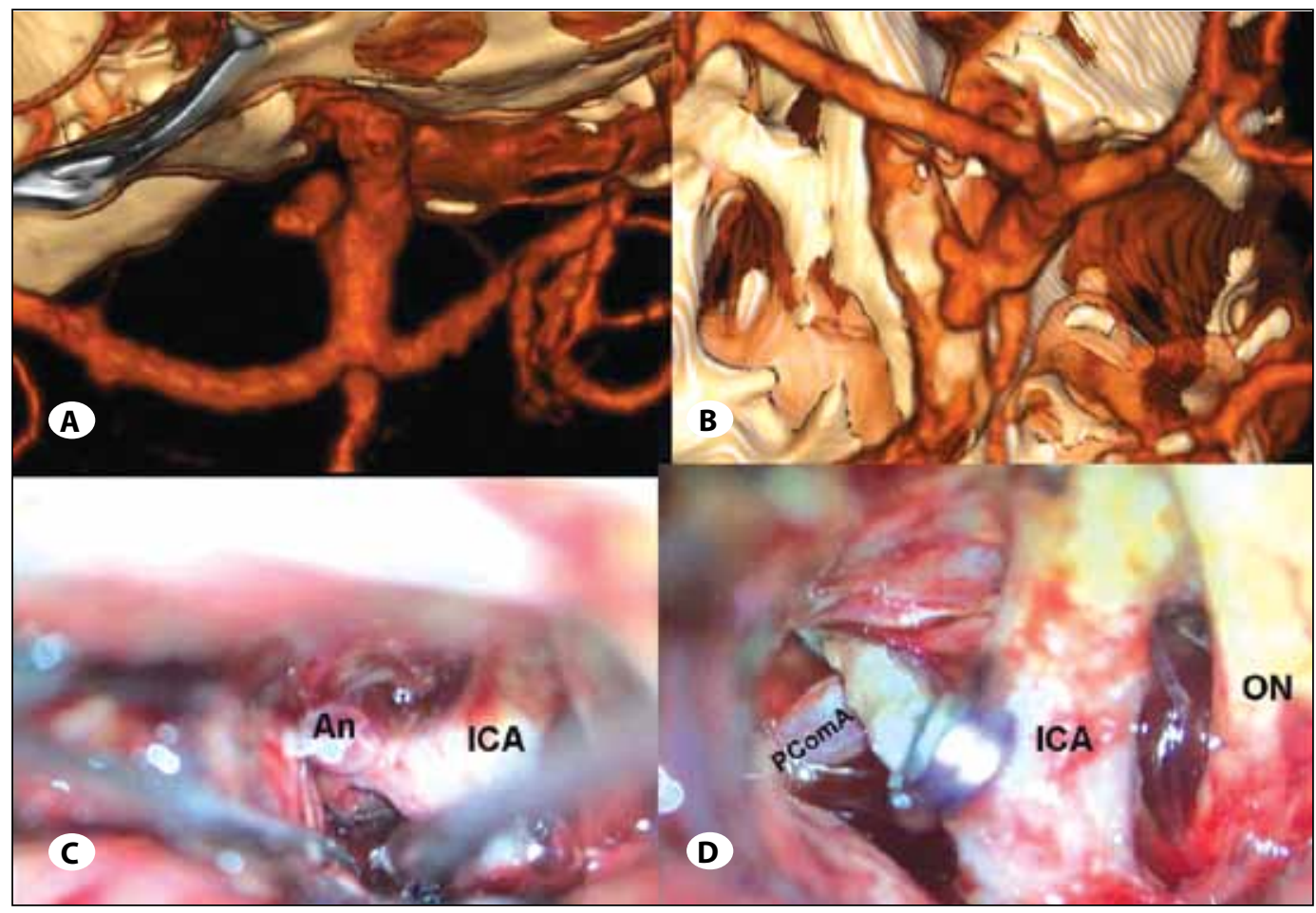

Figure 3: A) Bilobulated aneurysm with $4 \mathrm{~mm}$ diameter arising from left PCoA and projection of the anerysm is lateral and inferior (on view of pterional approach). B) View of posterior inferior (carotis ventro post) approach relationship between PCoA and bilobulated aneurysm. C) Intraoperative view of bilobulted aneurysm with lateral projection and rupture location at inferior lobule. D) View of clipping PCoA (1.4mm). ON; optic nerve, ICA; internal carotid artery, PComA; posterior communicating artery, An; Aneurysm.

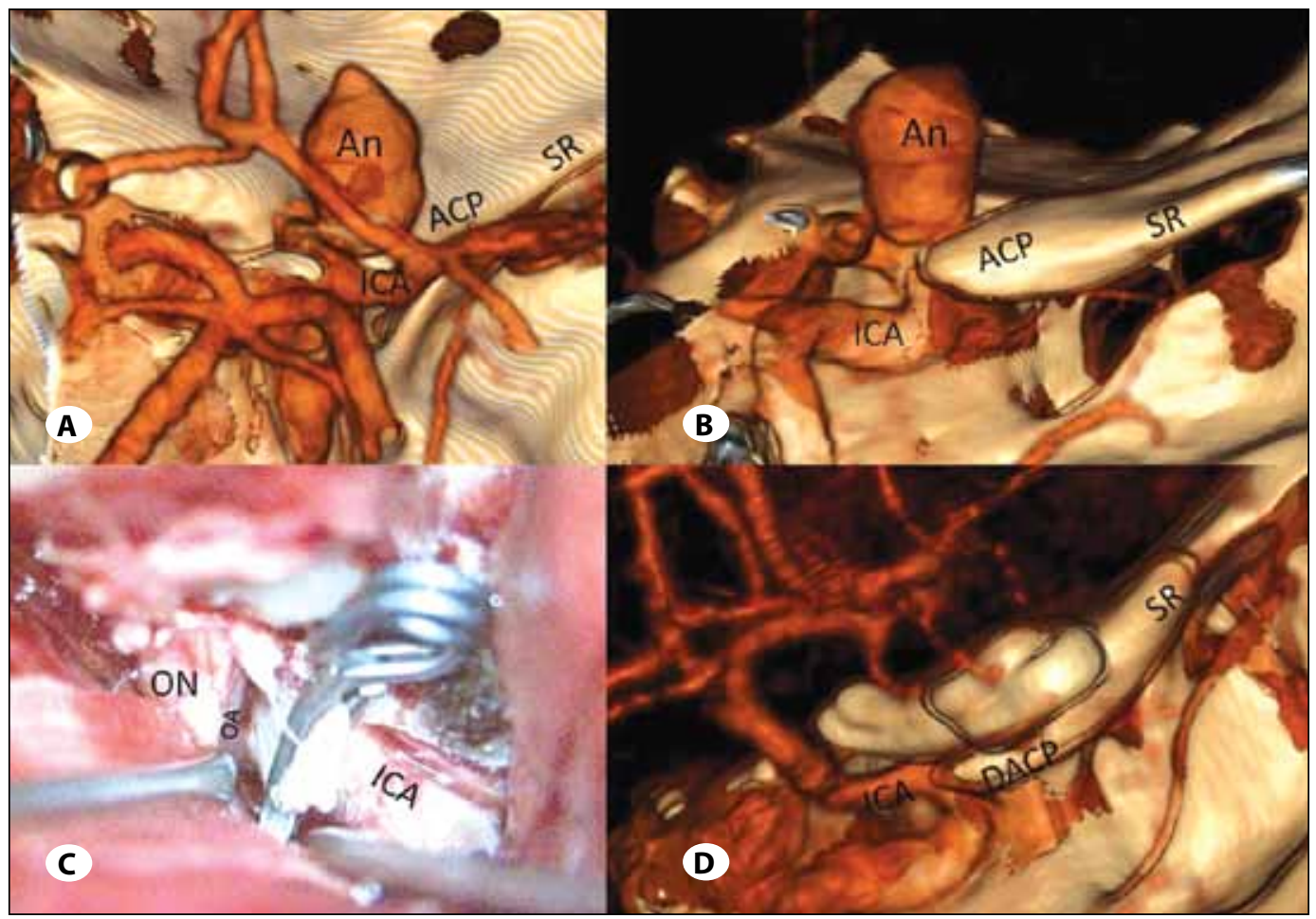

Figure 4: A) Three-dimensional CT angiography demonstrates paraclinoidal aneurysm of 18mm diameter with superior projection. B) Lateral view, after the some vascular structures are removed. C) After drilling of the clinoid process and optic canal unroofing, view of clipped aneurysm. D) Postoperative CTA reveals complete obliteration of the aneurysm. ICA; internal carotid artery, An; aneurysm, ACP; anterior clinoid process, SR; sphenoid ridge, ON; optic nerve, OA; ophthalmic artery, DACP; drilled anterior clinoid process. 
In comparisons of CTA and DSA, the efficiency of CTA in showing particularly small aneurysms has long been discussed. Although different values are used for aneurysm sizes, the results are close to each other. Single slice 3D CTA is a limited test with a sensitivity of $64 \%$ for $3 \mathrm{~mm}$ aneurysms and that of $83 \%$ for $3-4 \mathrm{~mm}$ aneurysms (10). Many reports have been published that describe different sensitivities of 4-slice CTA for intracranial aneurysms. Wintermark et al. reported 4-slice CTA in 50 patients; the achieved sensitivity for aneurysms was $94.8 \%$ on a per-aneurysm basis (24). Dammert et al. studied 39 patients with 48 aneurysms using 4-slice CTA and reported that the sensitivities were $83.3 \%$ for less than $4 \mathrm{~mm}$ and $100 \%$ for more than $13 \mathrm{~mm}$ (6). Teksam et al. evaluated detection of aneurysms in 100 patients and reported that the sensitivity of 4 -slice CTA was $84 \%$ for aneurysms less than $4 \mathrm{~mm}$ and $100 \%$ for aneurysms more than $10 \mathrm{~mm}$ (20). In another study, the same author investigated 103 patients with 49 small aneurysms $(<5 \mathrm{~mm})$ and the overall sensitivity of 4-slice CTA for small aneurysms was $85 \%$ (19). Sensitivity for aneurysms of
$4 \mathrm{~mm}$ or more was $97 \%-100 \%$ with 4 MSCTA $(20,24)$. Tipper G. has examined 57 patients with 16-slice CTA. They detected 35 aneurysms in 44 patients and did not detect any aneurysms in 13 patients. The sensitivity was $96.2 \%$ whereas the sensitivity for less than $3 \mathrm{~mm}$ was $91.7 \%$ (21).

Recently, there has been an increase in the number of studies on 64-slice CTA. Agid et al. studied 73 patients with 64-slice CTA and identified 46 aneurysms in 47 patients with a sensitivity of $98 \%$ and specificity of $98 \%$ and the rate of planning of treatment of aneurysms (surgery or endovascular) only with CTA was $95.7 \%$ (1). Lubicz et al. compared 48 patients with 64-slice CTA DSA and the sensitivity was $94 \%$ with a lower sensitivity for less than $3 \mathrm{~mm}$ at a rate of $70.4 \%$. The rate of planning effective treatment of aneurysms was $94.9 \%$ In this report, interobserver agreements for aneurysm detection and morphologic evaluation were slightly better than those reported in these studies. Improvement of interobserver agreement is probably related to the use of a 64-row multisection CT scanner (11). McKinney et al. reported that

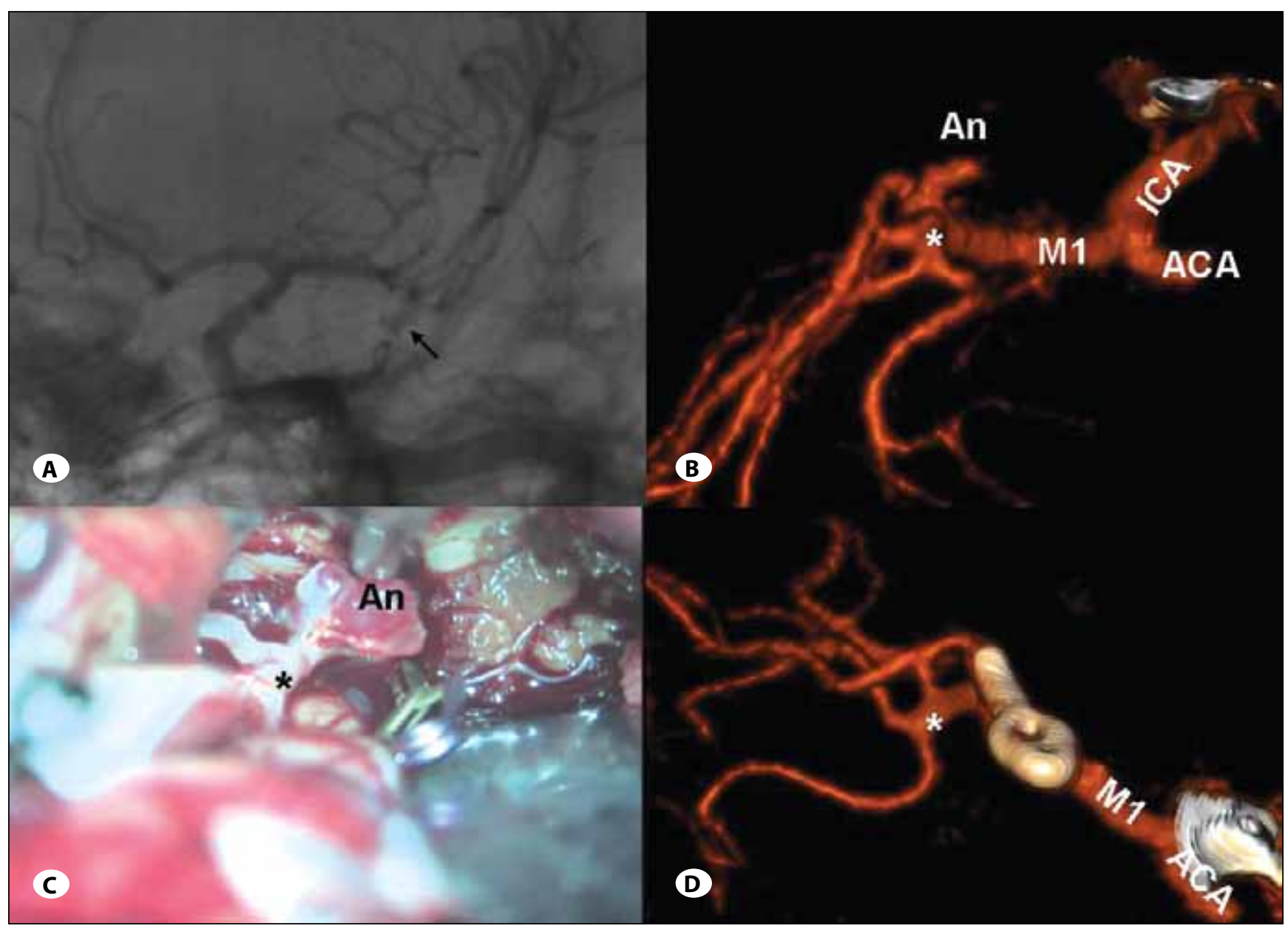

Figure 5: A) Oblique DSA image of SAH patient with negative CTA findings, demonstrates left MCA aneurysm with inferior projection (arrow). B) Aneurysm with $4 \mathrm{~mm}$ diameter and temporal lobe projection at MCA bifurcation just before early frontal branch is seen at re-evaluation. C) Intaroperative image shows prebifurcation of thin-walled aneurysm with temporal lobe projection after placement of temporary clipping on M1 segment. D) Postoperative CTA reveals complete obliteration of the aneurysm. ICA; Internal carotid artery, ACA; Anterior cerebral artery, M1; 1st segment of Middle cerebral artery, An; aneurysm, *; bifurcation of middle cerebral artery. 
when previous generation multislice CTs are compared with 64-slice CTA, 3D rotational DSA is the most effective method although 64-slice CTAs have increased efficiency in showing aneurysms smaller than $4 \mathrm{~mm}$. 64-slice CTA is excellent in the detection of intracranial aneurysms, and is better than 4- or 16-section CTAs; however, since aneurysms smaller than 3-4 $\mathrm{mm}$ in particular locations can be overlooked, it is suggested to use it in combination with 3D rotational DSA (13).

This preliminary study suggests that 64 slice CTA is excellent in the detection and delineation of intracranial aneurysms. When its efficiency for small aneurysms is looked at, the efficiency of showing small aneurysms of the technologically state of the art 64-slice CTs is seen to be lower than that achieved by Chen et al. in their study where they utilized a 16-slice device (3). This makes it inevitable that the detection of cerebral aneurysm in CTA is strongly dependent on the radiologist experience in reconstructions on the workstation. MIP and VRT may be time consuming but essential, and need, in many cases, long times on the workstation, variable between 15 and $30 \mathrm{~min}$, depending on operator experience.

In the preoperative period, we performed DSAs on only CTAnegative (22 patients) and aneurysm-detected (28 patients) patients in our patient group that required additional information. In our patient group, only 2 aneurysms that could not be detected initially were detected by DSA and during surgery. In the first one, a $3 \mathrm{~mm}$ MCA aneurysm, and in the second one, a PCOA $2 \mathrm{~mm}$ aneurysm was detected and the two aneurysms were visible retrospectively. The first aneurysm was small in size and adjacent to the sphenoid ridge. When the CTA was reexamined retrospectively, the aneurysm was clearly visible (Figure 5A-D). Therefore, we think that caution is required in the interpretation of small aneurysms adjacent to bones with multislice CTA. The second aneurysm was small in size and an adjacent bone obscured the view. The PCoA aneurysm ( $3 \mathrm{~mm}$ ) was at the proximity of the clinoid process in addition to the small size of the aneurysm. This patient had a carotid bifurcation aneurysm with a $22 \mathrm{~mm}$ diameter. When we saw the possibly bleeding aneurysm, we concluded that this aneurysm was missed during the insufficient examination at the workstation. Considering that our experience was based on limited number of cases, we believe that with longer examination time and more attention, these aneurysms can be identified. Pedersen et al. point out that as the experience of observers increase, the probability of missed aneurysms would decrease (15). Without prejudice to the importance of experience and careful examination at the workstation, the other well-known limitation of CTA for aneurysm detection concerns PcomA aneurysms and aneurysms located close to bony structures, such as paraclinoid aneurysms (20). In addition, it is generally difficult to distinguish a small PcomA aneurysm from an infundibular dilation, giving the false impression of a PcomA $(11,22)$. In our study, false-negative result in one case was related to aneurysms in such locations. This limitation is due to the close relationship with the clinoid process. Therefore, we believe that considerable caution is required in the interpretation of small aneurysms $(<3 \mathrm{~mm})$ arising from the PcomA or the paraclinoid ICA at CTA.
An accurate imaging study is also necessary to determine the indications for surgery in patients with aneurysms. Therefore, a detailed understanding of aneurysm morphology and the adjacent vasculature before clipping the aneurysmal neck is necessary to perform a safe and successful operation. Some aneurysm projections, such as a possible surgical view, are easy to obtain with 64-slice CTA but difficult to obtain with DSA. The ability to depict bone landmarks, another advantage of CTA over 2D-DSA, may play an important role in treatment planning. In our experience, the images obtained with the VRT method were far easier and quicker to evaluate than MIP images, and MIP alone was very insufficient. VRT gives better anatomical detail of the intracranial vasculature, and clearly has a role in the rapid evaluation of patients with acute $\mathrm{SAH}$. 64-slice CTA images exhibit more clarity and accuracy in the relationship of aneurysms to osseous structures and adjacent branch vessels. 3D-CTA provides the ability to reproduce a preoperative surgical view. The resulting preoperative images can lead to more successful surgery: it has sensitivity and specificity that are comparable to those of digital subtraction angiography in aneurysms larger than $2 \mathrm{~mm}$ and it performs quick reconstruction of 3-D images, which allows the surgeon to rotate the images to obtain surgical view images. Siablis et al. used a virtual coordinate system, which consisted of three coordinate axes and was utilized in order to replicate the same position in the operating room, for ACoA and MCA aneurysms. VRT images were rotated around every axis $(X, Y, Z)$ in order to find the optimum orientation for each patient. This meant the simultaneous complete exposure of the aneurysm neck and surrounding vessel. They conclude that preoperative simulation of the surgical view is feasible and facilitates aneurysm surgery (18). The term "surgical view" is not a well-devised definition. Matsumoto et al. used the term "surgical simulation images" (12) whereas Futami preferred the term "preop simulation views" (8) and asserted that these images were helpful for the determination of the appropriate surgical approach and that 3D-CTA could provide data similar to operative view in other studies $(16,17)$. In these studies, they suggest that with $3 \mathrm{D}$ reconstruction this may lead to a safer operation by making proximal control easier in the event of premature rupture. Chen W et al. used 16-slice CTA and DSA in intracranial aneurysm diagnosis on 244 patients and reviewed the intraoperative findings of the aneurysms. They found that in all of the 38 patients to which surgical treatment was applied, the surgical views correlated well with 16-slice CTA (4). Pechlivanis et al. found correlation between preoperative 3D CTA and aneurysm anatomy in a study with 100 patients performed only with CTA, even though aneurysms smaller than $2 \mathrm{~mm}$ and small lenticulostriate arteries could not be shown (14). Wada et al. obtained important information preoperatively about the rupture location of 13 of 14 MCA aneurysm via preoparative CTA (23).

In our study, the term 'operative simulation view' refers to a reproduced 3D image from 64-slice $C T$. We did not stick to the certain angles of the $X, Y, Z$ coordinate systems in obtaining surgical view data. Based on the surgical approach we 
considered for each aneurysm location, pictures or video clips were prepared through rotation from CTA data. The clips and pictures prepared at the angles where aneurysm neck was best visible were reevaluated and the most appropriate looking angle for surgery was determined. The main advantages of 3D-CTA images or video clips are that they can be rotated at any angle for clipping and the vessels around the aneurysm can be identified and preserved during surgery. In our case group, we saw that operation simulation views prepared with CTA helped us determine our approach to the aneurysm in surgery and that the surgeon had a clearer picture of the 3D aneurysm configuration in mind. 3D-CTA can help to reduce the possible early ruptures during surgery. Preoperative simulation of the surgical view is feasible, not time consuming and facilitates aneurysm surgery. In our study, 247 patients with 291 aneurysms were examined. Surgical views obtained with 64-slice CTA images correlated well with the surgical findings except 3 cases. In one of the cases, it was not possible to clip the aneurysm due to the LS arteries projecting from the aneurysm neck. In another case, the aneurysm had a larger than the expected neck with calcified plaque. In a third case, the MCA aneurysm was hidden behind the main trunk due to over-turning of the patient head and this was realized at the end of the Sylvian fissure dissection. Except those 3 cases, the 3D images were a useful tool for surgical clipping in nearly all cases.

In conclusion, apart from being less invasive and faster, 3D-CTA allows the surgeon to rotate the images as a surgical view, facilitating a more accurate understanding of the anatomic relationships between the parent artery and aneurysm neck. The reason for its production is to simulate the intraoperative view of an aneurysm and to help the neurosurgeon to conceptualize its morphological features before surgery. Keeping in mind that small aneurysms $(\leq 2 \mathrm{~mm})$ may not be seen by CTA, DSA should be performed to plan additional strategies in addition to clipping giant and complex aneurysms where special flow dynamics are important. 3D rotational angiography seems to be advantageous with regards to the current dynamics information and 3D-CTA in that it is less invasive and can show bone structure together with the aneurysm.

\section{REFERENCES}

1. Agid R, Lee SK, Willinsky R, Farb RI, terBrugge KG: Acute subarachnoid hemorrhage: Using 64-slice multidetector CT angiography to "triage" patients' treatment. Neuroradiology 48:787-794,2006

2. Anderson GB, Steinke DE, Petruk KC, Ashforth R, Findlay JM: Computed tomographic angiography versus digital subtraction angiography for the diagnosis and early treatment of ruptured intracranial aneurysms. Neurosurgery 45:13151320,1999

3. Chen W, Wang J, Xing W, Xu Q, Qiu J, Huang Q, Sun Y, Yu S, Peng Y: Accuracy of 16-row multislice computerized tomography angiography for assessment of intracranial aneurysms Surg Neurol 71(1):32-42,2009
4. Chen W, Yang Y, Xing W, Qiu J, Peng Y: Sixteen-row multislice computed tomography angiography in the diagnosis and characterization of intracranial aneurysms: Comparison with conventional angiography and intraoperative findings $J$ Neurosurg 108(6):1184-1191,2008

5. Cloft HJ, Joseph GJ, Dion JE: Risk of cerebral angiography in patients with subarachnoid hemorrhage, cerebral aneurysm, and arteriovenous malformation: A meta-analysis. Stroke 30:317-320,1999

6. Dammert $S$, Krings $T$, Moller-Hartmann W, Ueffing $E$, Hans FJ, Willmes $K$, Mull $M$, Thron A: Detection of intracranial aneurysms with multislice CT: Comparison with conventional angiography. Neuroradiology 46:427-434,2004

7. Debrun GM, Aletich VA, Kehrli P, Misra M, Ausman Jl, Charbel F: Selection of cerebral aneurysms for treatment using Guglielmi detachable coils: The preliminary University of Illinois at Chicago experience. Neurosurgery 43:12811287,1998

8. Futami K, Nakada M, Iwato M, Kita D, Miyamori T, Yamashita J: Simulation of clipping position for cerebral aneurysms using three-dimensional computed tomography angiography. Neurol Med Chir 44:6-13,2004

9. Kaufmann TJ, Huston J 3rd, Mandrekar JN, Schleck CD, Thielen KR, Kallmes DF: Complications of diagnostic cerebral angiography: Evaluation of 19,826 consecutive patients. Radiology 243(3):812-819,2007

10. Korogi Y, Takahashi M, Katada K, Ogura Y, Hasuo K, Ochi M, Utsunomiya $\mathrm{H}$, Abe T, Imakita S: Intracranial aneurysms: Detection with three-dimensional CT angiography with volume rendering-Comparison with conventional angiographic and surgical findings. Radiology 211:497-506,1999

11. Lubicz B, Levivier M, François O, Thoma P, Sadeghi N, Collignon $\mathrm{L}$, Balériaux D: Sixty-four-row multisection CT angiography for detection and evaluation of ruptured intracranial aneurysms: Interobserver and intertechnique reproducibility. AJNR Am J Neuroradiol 28:1949-1955,2007

12. Matsumoto $M$, Sato $M$, Nakano $M$, Endo $Y$, Watanabe $Y$, Sasaki T, Suzuki K, Kodama N: Three-dimensional computerized tomography angiographyguided surgery of acutely ruptured cerebral aneurysms. J Neurosurg 94:718-727,2001

13. McKinney AM, Palmer $C S$, Truwit $C L$, Karagulle $A$, Teksam M: Detection of aneurysms by 64-section multidetector CT angiography in patients acutely suspected of having an intracranial aneurysm and comparison with digital subtraction and 3D rotational angiography. AJNR Am J Neuroradiol 29:594-602,2008

14. Pechlivanis I, Schmieder K, Scholz M, König M, Heuser L, Harders A: 3-Dimensional computed tomographic angiography for use of surgery planning in patients with intracranial aneurysms. Acta Neurochir (Wien)147(10):1045-1053,2005

15. Pedersen HK, Bakke SJ, Hald JK, Skalpe IO, Anke IM, Sagsveen $\mathrm{R}$, Langmoen IA, Lindegaard KE, Nakstad PH: CTA in patients with acute subarachnoid haemorrhage. A comparative study with selective, digital angiography and blinded, independent review. Acta Radiol 42(1):43-49,2001 
16. Satoh T, Onoda K, Tsuchimoto S: Intraoperative evaluation of aneurysmal architecture: Comparative study with transluminal images of 3D MR and CT angiograms. Am J Neuroradiol 24(10):1975- 1981,2003

17. Schmid-Elsaesser R, Muacevic A, Holtmannspotter M, Uhl E, Steiger HJ: Neuronavigation based on CT Angiography for surgery of intracranial aneurysms: Primary experience with unruptured aneurysms. Minim Invasive Neurosurg 46:269277,2003

18. Siablis D, Kagadis GC, Karamessini MT, Konstantinou D, Karnabatidis D, Petsas T, Nikiforidis GC: Intracranial aneurysms: Reproduction of the surgical view using 3D-CT angiography. Eur J Radiol 55(1):92-95,2005

19. Teksam M, McKinney A, Cakir B, Truwit CL: Multi-slice CT angiography of small cerebral aneurysms: Is the direction of aneurysm important in diagnosis? Eur J Radiol 53:454462,2005

20. Teksam M, McKinney A, Casey S, Asis M, Kieffer S, Truwit $\mathrm{CL}$ : Multi-section CT angiography for detection of cerebral aneurysms. AJNR Am J Neuroradiol 25: 1485-1492,2004

21. Tipper G, U-King-Im JM, Price SJ, Trivedi RA, Cross JJ, Higgins NJ, Farmer R, Wat J, Kirollos R, Kirkpatrick PJ, Antoun NM, Gillard JH: Detection and evaluation of intracranial aneurysms with 16-row multislice CT angiography. Clin Radiol 60:565572,2005
22. Villablanca JP, Jahan R, Hooshi P, Lim S, Duckwiler G, Patel A, Sayre J, Martin N, Frazee J, Bentson J, Vinuela F: Detection and characterization of very small cerebral aneurysms by using 2D and 3D helical CT angiography. AJNR Am J Neuroradiol 23:1187-1198,2002

23. Wada K, Arimoto $H$, Ohkawa $H$, Shirotani T, Matsushita $Y$, Takahara T: Usefulness of preoperative three-dimensional computed tomographic angiography with two-dimensional computed tomographic imaging for rupture point detection of middle cerebral artery aneurysms. Neurosurgery 62 Suppl 1:126-132,2008

24. Wintermark M, Uske A, Chalaron M, Regli L, Maeder P, Meuli R, Schnyder P, Binaghi S: Multislice computerized tomography angiography in the evaluation of cerebral aneurysms: A comparison with intraarterial digital subtraction angiography. J Neurosurg 98:828-836,2003

25. Zouaoui A, Sahel M, Marro B, Clemenceau S, Dargent N, Bitar A, Faillot T, Capelle L, Marsault C: Three-dimensional computed tomographic angiography in detection of cerebral aneurysms in acute subarachnoid hemorrhage. Neurosurgery 41:125-130,1997 